
\title{
25 Research Soure \\ Outcomes of Patients Falling from Heights in the Level-I Trauma Center: A 10-Year Multi-Center Study
}

Pei-Hsiu Wang

National Taiwan University Hospital

Chun-Hsiang Huang

National Taiwan University Hospital

I-Chung Chen

National Taiwan University Hospital Yun-Lin Branch: National Taiwan University Hospital Yun Lin Branch

Edward Pei-Chuan Huang

National Taiwan University Hospital Hsin-Chu Branch

Wan-Ching Lien ( $\triangle$ wanchinglien@ntu.edu.tw )

National Taiwan University Hospital

Chien-Hua Huang

National Taiwan University Hospital

Research article

Keywords: falling from height, cardiac arrest, falling height, injury severity score.

Posted Date: January 26th, 2021

DOI: https://doi.org/10.21203/rs.3.rs-152572/v1

License: (c) (i) This work is licensed under a Creative Commons Attribution 4.0 International License.

Read Full License 


\section{Abstract}

Background: Falls from height and fall-related injuries are global healthcare challenges. Falls cause a significant proportion of urban trauma with high mortality rates, being the leading cause of accidental deaths. This study aims to investigate the outcomes of patients after free falls in the level 1 trauma centers in Taiwan.

Methods: This retrospective cohort study was conducted at the emergency departments of the National Taiwan University Hospital, and its two branches, the Hsin-Chu branch and the Yun-Lin branch between January 2010 and September 2020. Adult patients with free falls higher than one story were enrolled. Clinical data were obtained from electronic medical records. Odds ratios (OR) were computed with 95\% confidence intervals (Cls) for significant parameters for mortality in the logistic regression models.

Results: A total of 371 patients were enrolled and 101 patients suffered from out-of-hospital cardiac arrests (OHCAs). The mortality rate was $98 \%$ and $11 \%$ in patients with and without OHCA and the majority of deaths occurred within one day of the fall. Falling heights were significantly $(O R, 1.14,95 \%$ Cls, 1.10-1.19) related to OHCAs. Among the patients without cardiac arrests on arrival, a higher injury severity score (ISS) was significantly (OR, 1.10, 95\% Cls, 1.07-1.14) related to deaths. Serious head/neck (OR, 5.19, 95\% Cl, 2.21-12.19) and chest injury (OR, 2.39, 95\% Cls, 1.10-5.17) were significantly fatal injuries.

Conclusion: Patients with falls-related OHCA had poor outcomes and higher falling height was significantly related to cardiac arrests. A higher ISS was related to death during admission. A better understanding of the characteristics allows for resource allocation for patients with free-fall trauma.

\section{Background}

Falls from heights and fall-related injuries are global healthcare challenges. Falls cause a significant proportion of trauma with high mortality rates, being the second leading cause of accidental deaths following road traffic accidents (1).

The injury mechanism of free falls is abrupt vertical deceleration, and the impact force is determined largely by the vertical distance of the fall (2). The uniqueness and complexity of each fall contribute to various orthopedic, neurological, and surgical injuries. It commonly involves multi-organ injuries, and delayed diagnosis and management are associated with high mortality and morbidity. A better understanding of the characteristics and risk factors for mortality can help reduce associated morbidity, mortality, and the resultant burden on scarce healthcare facilities, whether in the pre-hospital or hospital settings (3). 
Centralized trauma care for severely injured patients by higher-level trauma centers has shown some benefit on patients' outcomes (4). Insights from level-I trauma centers are still limited. Also, the evidence is controversial for prognostic factors regarding falls from heights. Fatal height was reported as more than $6 \mathrm{~m}$ (5-7); however, autopsy results showed that fatal falls could occur under $6 \mathrm{~m}$ (8). A severe head injury could be a significant factor for mortality following falls from more than $6 \mathrm{~m}$ (9). However, a severe head injury could occur in patients who fell from under $3 \mathrm{~m}$ (10). The relationship between falling heights, injury patterns, and mortality is still unclear so that more evidence is needed.

Therefore, this study aims to investigate the characteristics and outcomes of patients falling from heights at three level-I trauma centers in 10 years in Taiwan. The factors associated with mortality were also explored.

\section{Methods}

\section{Study design and setting}

This retrospective cohort study was conducted at the Emergency Departments (EDs) of the National Taiwan University Hospital (NTUH), and its two branches, the Hsin-Chu branch and the Yun-Lin branch between January 2010 and September 2020. The EDs had approximately 120,000, 60000, and 50000 visits in the NTUH, the Hsin-Chu branch, and the Yun-Lin branch, respectively. All of them were level-I trauma centers. This study was approved by the Institutional Review Board of the NTUH (202009091RINC) and registered at ClinicalTrials.gov (NCT04596436).

\section{Patient Inclusion Criteria}

Adult patients aged more than 20 years and having fall-from-height injuries were enrolled. Falls from heights included falls from scaffolding, a building, or another structure of higher than one story were enrolled. Falls related to traffic accidents or from mountains were excluded. All patients were resuscitated according to the Advanced Trauma Life Support (ATLS) standards. Trauma activation was initiated in every patient.

\section{Data Collection}

Clinical data were retrospectively reviewed from the electronic medical records and emergency medical service, including age, sex, falling height, cause of the fall, the type of ground on which the patient fell, injury severity scores (ISS), patterns of injuries, out-of-hospital cardiac arrests (OHCAs) on arrival at the $E D$, death or survival during the same admission, and length of stay. Falling heights were calculated against the $3.6 \mathrm{~m} /$ storey standards $(11,12)$. ISS was defined as the sum of the squares of the highest Abbreviated Injury Scale (AIS) score in each of the three most severely injured body regions. 
Patterns of injury were collected based on the findings of computed tomography (CT) and described according to the body regions of ISS: head, face, chest, abdomen, and extremities. Serious injury was defined as AIS $\geqq 3$ for any body region. The body position on impact was difficult to investigate accurately without a witness on the scene; hence, this factor was not included in this study.

These patients were divided into those with OHCA and non-OHCA on arrival at the ED. Non-OHCA victims were further categorized into survivors and non-survivors. Between-group differences for the parameters were investigated.

\section{Statistical analysis}

Statistical analyses were performed using Statistical Analysis System software (SAS 9.4, Cary, North Carolina, USA). Data were analyzed with the Chi-square test for categorical variables and the t-test for continuous variables. Logistic regression was applied for possible predictive factors for OHCAs.

Covariates in this model included age, sex, falling height, cause of falls, type of the ground, and hospitals. Also, logistic regression was applied for possible predictors for those without cardiac arrests on arrival at the ED but died during the same admission. Covariates in this model included age, sex, falling height, cause of falls, hospitals, ISS, or patterns of injury. Odds ratios (OR) were computed with $95 \%$ confidence intervals (Cls) for significant parameters. A p-value of less than 0.05 was considered statistically significant.

\section{Results}

During the 10-year study period, 371 patients were included (Table 1, Fig. 1) from three level-I trauma centers. All of the falls impacted on hard ground. Although the numbers of patients differed in the three hospitals, there were no significant differences in mortality rates of patients with and without OHCAs (Supplementary Table 1). 
Table 1

Characteristics of the patients with falls from height

\begin{tabular}{|llll|}
\hline & Out-of-hospital arrest & Non-OHCA & \\
\cline { 2 - 4 } & $(\mathbf{n = 1 0 1 )}$ & $(\mathbf{n = 2 7 0 )}$ & p-Value* $^{*}$ \\
\hline Age (years) ${ }^{\dagger}$ & $46.1 \pm 17.1$ & $48.7 \pm 16.4$ & 0.1815 \\
\hline female gender, $n(\%)$ & $36(36 \%)$ & $63(23 \%)$ & 0.017 \\
\hline Cause of the falls & & & \\
\hline Suicidal, $n(\%)$ & $68(67 \%)$ & $79(29 \%)$ & $<0.0001$ \\
\hline Unintentional, $n(\%)$ & $33(33 \%)$ & $191(71 \%)$ & $<0.0001$ \\
\hline Workplace, $n(\%)$ & $16(16 \%)$ & $138(51 \%)$ & $<0.0001$ \\
\hline Height, meters ${ }^{\dagger}$ & $22.1 \pm 12.5$ & $9.0 \pm 6.6$ & $<0.0001$ \\
\hline Hospital & & $187(69 \%)$ & 0.0005 \\
\hline National Taiwan University Hospital & $88(87 \%)$ & $72(27 \%)$ & 0.0002 \\
\hline Hsin-Chu Branch & $9(10 \%)$ & $11(4 \%)$ & 0.9605 \\
\hline Yun-Lin Branch & $4(4 \%)$ & $20.4 \pm 14.4$ & $<0.0001$ \\
\hline Injury severity scores ${ }^{\dagger}$ & 75 & - & \\
\hline Return of spontaneous circulation at the ED ${ }^{\ddagger}$ & $8(8 \%)$ & $239(89 \%)$ & $<0.0001$ \\
\hline Survival to discharge & $2(2 \%)$ & & \\
\hline${ }^{*}$ Comparisons between patients with and without out-of-hospital cardiac arrest. & \\
\hline${ }^{\dagger}$ Expressed as mean \pm standard deviation. & & & \\
\hline${ }^{\ddagger}$ ED, Emergency Department & & & \\
\hline
\end{tabular}

One hundred and one patients experienced cardiac arrests on arrival at the EDs. Of them, 8 patients achieved the return of spontaneous circulation and only 2 survived to hospital discharge. The mortality rate was $98 \%$ and the majority of deaths occurred within one day after the falls (Fig. 2). CT was only performed in successfully resuscitated patients; therefore, the CT findings were not included in the analysis in OHCA group.

Females, suicidal falls, higher falling heights were associated positively with OHCAs, as well as the hospitals. In the logistic regression analysis, falling heights were significantly $(\mathrm{OR}, 1.14,95 \% \mathrm{Cl}, 1.10-$ 1.19) related to OHCA after adjusting for gender, suicidal falls, and hospitals. 
Two hundred and seventy patients survived on arrival at the EDs (Table 2) and all of them received CT. Although most of the patients (239 patients, $89 \%$ ) survived to discharge, the majority of the deaths occurred on the first day after the falls (Fig. 2). Older ages and higher ISS were associated with in-hospital mortality. In the logistic regression analysis, higher ISS was significantly $(\mathrm{OR}, 1.10,95 \% \mathrm{Cl}, 1.07-1.14)$ related to deaths after adjusting for age. 
Table 2

Characteristics of the patients without cardiac arrest on arrival at the emergency department.

\begin{tabular}{|c|c|c|c|}
\hline & Survivors & Deaths & p-Value* \\
\hline & $(n=239)$ & $(n=31)$ & \\
\hline Age (years) ${ }^{\dagger}$ & $47.9 \pm 15.8$ & $55.0 \pm 19.5$ & 0.022 \\
\hline Female gender, $n(\%)$ & $58(24 \%)$ & $5(17 \%)$ & 0.314 \\
\hline Cause of the falls & & & \\
\hline Suicidal, $n(\%)$ & $69(29 \%)$ & $10(32 \%)$ & 0.697 \\
\hline Unintentional, $n(\%)$ & $170(71 \%)$ & $21(68 \%)$ & 0.697 \\
\hline Workplace, $n(\%)$ & $122(51 \%)$ & $16(52 \%)$ & 0.953 \\
\hline Height, meters ${ }^{\dagger}$ & $8.9 \pm 6.6$ & $9.3 \pm 6.5$ & 0.732 \\
\hline Hospital & & & \\
\hline National Taiwan University Hospital & $165(69 \%)$ & $22(71 \%)$ & 0.827 \\
\hline Hsin-Chu Branch & $64(27 \%)$ & $8(26 \%)$ & 0.908 \\
\hline Yun-Lin Branch & $10(4 \%)$ & $1(3 \%)$ & 0.799 \\
\hline Injury severity scores ${ }^{\dagger}$ & $17.9 \pm 10.9$ & $39.5 \pm 22.1$ & $<0.0001$ \\
\hline Injury patterns & & & \\
\hline AIS Head $/$ neck $\geqq 3, n(\%)^{\ddagger}$ & $82(34 \%)$ & $23(74 \%)$ & $<0.0001$ \\
\hline AIS Face $\geqq 3, n(\%)^{\ddagger}$ & $7(3 \%)$ & $2(6 \%)$ & 0.304 \\
\hline AlS Chest $\geqq 3, n(\%)^{\ddagger}$ & $87(36 \%)$ & $17(55 \%)$ & 0.047 \\
\hline AIS Abdomen $\geqq 3, n(\%)^{\ddagger}$ & $52(22 \%)$ & $8(26 \%)$ & 0.610 \\
\hline AIS Extremities $\geqq 3, n(\%)^{\ddagger}$ & $69(29 \%)$ & $9(29 \%)$ & 0.985 \\
\hline Hospital stay, days $^{\dagger}$ & $18.3 \pm 20.3$ & $2.3 \pm 3.7$ & $<0.0001$ \\
\hline${ }^{*}$ Comparisons between survivors anc & & & \\
\hline${ }^{\dagger}$ Expressed as mean \pm standard dev & & & \\
\hline${ }^{\ddagger}$ AIS, Abbreviated Injury Scale & & & \\
\hline
\end{tabular}


Because ISS was the sum of the squares of the highest AIS score in each of the three most severely injured body regions, the regression model was re-built and ISS was replaced by the head/neck, face, chest, abdominal, and extremities injuries to investigate patterns of injury. Serious head/neck (OR, 5.19, $95 \% \mathrm{Cl}, 2.21-12.19)$ and chest injury (OR, $2.39,95 \% \mathrm{Cl}, 1.10-5.17)$ with AIS score $\geqq 3$ were strongly associated with deaths after adjusting for age and other injuries. The most common head injury was subarachnoid hemorrhage, followed by skull fracture and subdural hemorrhage (Supplementary Tables 2). The most common chest injury was rib fracture, followed by hemothorax and lung contusion (Supplementary Tables 3).

\section{Discussion}

Falls from heights had become a leading cause of traumatic deaths (1). This study investigated the outcomes of patients with free falls in three level-I trauma centers in 10 years. Although the overall mortality rate was $35 \%, 98 \%$ of patients with OHCA were declared death after aggressive resuscitation. By contrast, only $11 \%$ of non-OHCA patients died in the hospital. Disparities occurred in the prognostic predictors in patients with and without cardiac arrests. The falling height was associated with OHCAs; a higher ISS was associated with mortality in patients without OHCAs and serious head and chest injuries have a significant impact.

Patients with OHCAs were usually excluded in the previous studies regarding free-fall trauma and little is known about the prognostic factors and injury patterns. The mortality rate would be underestimated with the exclusion of these patients. Hence, the inclusion of the patients with OHCA was essential to better understand the predictors and outcomes among fall-related deaths.

A previous study reported that more than half of the traumatic deaths after falls occurred out-of-hospital (13). In a Taiwanese study, $80 \%$ of the fall-related OHCAs failed to survive, whether they were transferred to teaching hospitals or not (14). The survival rates of traumatic OHCAs were significantly lower than those of medical cardiac arrests, although the trauma patients were younger (15). Although the outcomes were better in severely injured patients in level-I trauma center (16), death after aggressive resuscitation was declared for $98 \%$ of the patients with OHCAs in this study. It implied that free-fall patients with cardiac arrests did have a grave prognosis, even in trauma centers.

Falls from height is a common major trauma in EDs. The emergency medical services (EMS) system plays an essential role in obtaining important pre-hospital information, such as falling height, place, and cause. Also, because fall-related OHCAs had dismal outcomes, trauma bypass allocating this kind of patient to the level I trauma center should be reconsidered. However, falls often occur in public spaces (15). Obtaining death claims on the scene without transferring to the hospital would be difficult in Chinese society.

Evidence regarding the prognostic factors for free-fall trauma is still controversial. Previous studies have shown that fatal falls were associated with multiple factors, such as older age, falling from a height of more than $6 \mathrm{~m}$, head injury, and higher ISS $(2,5,6,9,17)$. The results in our study showed that the falling 
height was significantly related to OHCAs after adjusting for other confounders. The average falling height of cardiac arrests was 22 meters, approximately 6-story height. On the contrary, there was no significant impact of falling height on the outcomes of patients without OHCA.

The ISS was introduced in 1974 (18). It is calculated until all injuries are known, being the gold standard for evaluating trauma patients and a strong predictor of mortality, morbidity, and hospitalization time after trauma (19). Our study demonstrated that ISS was significantly higher among deaths than survivors in non-OHCA patients. To investigate the relationship between patterns of injury and mortality, body regions were included for analysis. Regardless of falling heights, serious head and chest injuries with AIS $\geqq 3$ were independent predictive factors of mortality. The results implied that low-height falls could cause serious head and chest injuries and even death.

Notably, 16 deaths (52\%) occurred in the working place. In a study by Kim et al., those wearing safety helmets were less likely to have intracranial injuries in work-related falls (18). Head injury had a substantial effect on mortality among non-OHCA patients in this study, so helmets were a potentially effective prevention method against work-related traumatic brain injury $(18,19)$.

Despite these contributions, there were limitations in this study. First, because our study was a retrospective design, some data was missing, such as body position on impact. Second, CT was not performed in patients with OHCAs that patterns of injury could not be elucidated. Third, our results may not reflect the epidemiological profile of the entire population of the whole country. Our hospital and its affiliated hospitals were teaching hospitals where the disease pattern would be more severe and complicated. The mortality rate might be overestimated in this study.

\section{Conclusions}

Disparities existed in outcomes and predictors of mortality among free-fall patients with and without OHCAs. The mortality rate was $98 \%$ and $11 \%$ in patients with and without OHCAs and the majority of deaths occurred within the first day. Falling heights were associated with OHCAs. A higher ISS was related to death during admission. A better understanding of the characteristics allows for resource allocation for patients falling from heights.

\section{Abbreviations}

Emergency Department (ED); National Taiwan University Hospital (NTUH); Advanced Trauma Life Support (ATLS); Injury Severity Score (ISS); out-of-hospital cardiac arrest (OHCA); Abbreviated Injury Scale (AIS); computed tomography (CT); odds ratio (OR); confidence intervals (Cls); emergency medical services (EMS)

\section{Declarations}


Ethics approval and consent to participate: This study was approved by the Institutional Review Board of the NTUH (202009091RINC) and registered at ClinicalTrials.gov (NCT04596436).

Consent for publication: Not applicable

Availability of data and materials: Not applicable

Competing interests: The authors declare that they have no competing interests

Funding: Not applicable

Authors' contributions: $\mathrm{PH}$ and WC conceived the study and designed the trial. $\mathrm{CH}, \mathrm{IC}, \mathrm{EP}, \mathrm{CH}$, and WC analyzed and interpreted the data. PH and WC drafted the manuscript, and all authors contributed substantially to its revision. WC critically revised the manuscript for important intellectual content and takes responsibility for the paper as a whole. All authors read and approved the final manuscript.

Acknowledgements: Not applicable

\section{References}

1. Rockett IRH, Regier MD, Kapusta ND, Coben JH, Miller TR, Hanzlick RL, et al. Leading causes of unintentional and intentional injury mortality: United States, 2000-2009. Am J Public Health. 2012;102(11):e84-92.

2. Tan S, Porter K. Free fall trauma. Trauma. 2006;8(3):157-67.

3. Jain V, Jain S, Dhaon B. A Multi Factorial Analysis of the epidemiology of Injuries from Falls from Heights. International Journal of Critical IIIness Injury Science. 2014;4(4):283-7.

4. Zacher MT, Kanz KG, Hanschen M, Häberle S, van Griensven M, Lefering R, et al. Association between volume of severely injured patients and mortality in German trauma hospitals. Br J Surg. 2015;102(10):1213-9.

5. Icer M, Guloglu C, Orak M, Ustundag M. Factors affecting mortality caused by falls from height. Ulusal travma ve acil cerrahi dergisi = Turkish. journal of trauma emergency surgery: TJTES. 2013;19(6):529-35.

6. Alizo G, Sciarretta JD, Gibson S, Muertos K, Romano A, Davis J, et al. Fall from heights: does height really matter? Eur J Trauma Emerg Surg. 2018;44(3):411-6.

7. Steedman DJ. Severity of free-fall injury. Injury. 1989;20(5):259-61.

8. Peng T-A, Lee C-C, Lin J, Shun C, Shaw K-P, Weng T. Fatal Falls from Height in Taiwan. Journal of forensic sciences. 2014;59.

9. Liu CC, Wang CY, Shih HC, Wen YS, Wu JJ, Huang Cl, et al. Prognostic factors for mortality following falls from height. Injury. 2009;40(6):595-7.

10. Angela $B$, Klaus $P$, Kara K. Traumatic brain injury in high versus low falls in young children and adolescents: a retrospective analysis. Journal of Neurosurgery: Pediatrics PED. 2018;22(3):233-7. 
11. Mathis RD, Levine SH, Phifer S. An analysis of accidental free falls from a height: the 'spring break' syndrome. The Journal of trauma. 1993;34(1):123-6.

12. Risser D, Bonsch A, Schneider B, Bauer G. Risk of dying after a free fall from height. Forensic Sci Int. 1996;78(3):187-91.

13. Beck B, Smith K, Mercier E, Gabbe B, Bassed R, Mitra B, et al. Differences in the epidemiology of outof-hospital and in-hospital trauma deaths. PloS one. 2019;14(6):e0217158.

14. Lai $\mathrm{CY}$, Tsai SH, $\mathrm{Lin} \mathrm{FH}, \mathrm{Chu} \mathrm{H}, \mathrm{Ku} \mathrm{CH}, \mathrm{Wu} \mathrm{CH}$, et al. Survival rate variation among different types of hospitalized traumatic cardiac arrest: A retrospective and nationwide study. Medicine. 2018;97(28):e11480.

15. Escutnaire J, Genin M, Babykina E, Dumont C, Javaudin F, Baert V, et al. Traumatic cardiac arrest is associated with lower survival rate vs. medical cardiac arrest - Results from the French national registry. Resuscitation. 2018;131:48-54.

16. DiMaggio C, Ayoung-Chee P, Shinseki M, Wilson C, Marshall G, Lee DC, et al. Traumatic injury in the United States: In-patient epidemiology 2000-2011. Injury. 2016;47(7):1393-403.

17. Turgut K, Sarihan ME, Colak C, Guven T, Gur A, Gurbuz S. Falls from height: A retrospective analysis. World journal of emergency medicine. 2018;9(1):46-50.

18. Baker SP, O'Neill B, Haddon W Jr, Long WB. The injury severity score: a method for describing patients with multiple injuries and evaluating emergency care. The Journal of trauma. 1974;14(3):187-96.

19. MacKenzie EJ. Injury severity scales: overview and directions for future research. Am J Emerg Med. 1984;2(6):537-49.

\section{Figures}




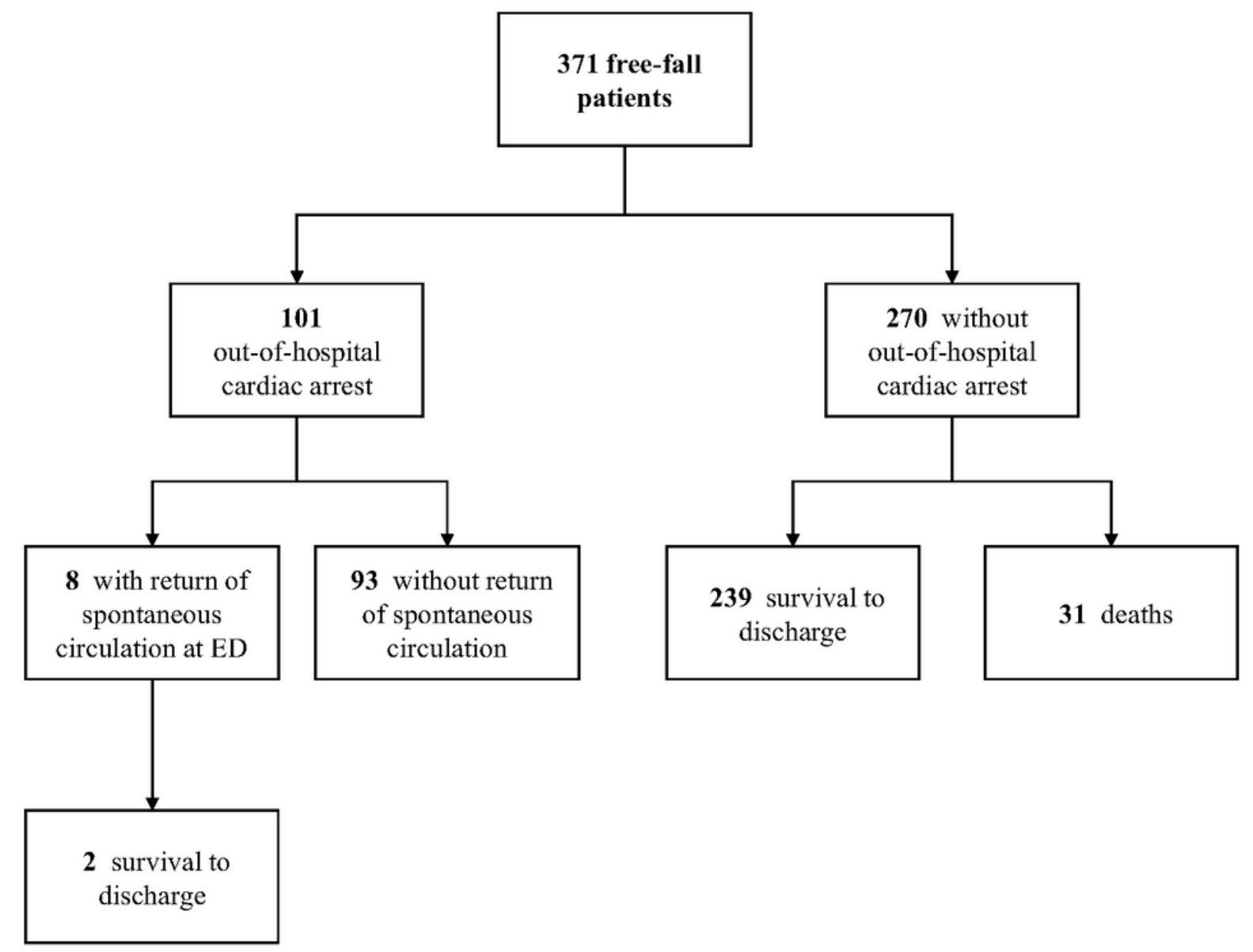

\section{Figure 1}

The study diagram. 
A. Patients with out-of-hospital cardiac arrest

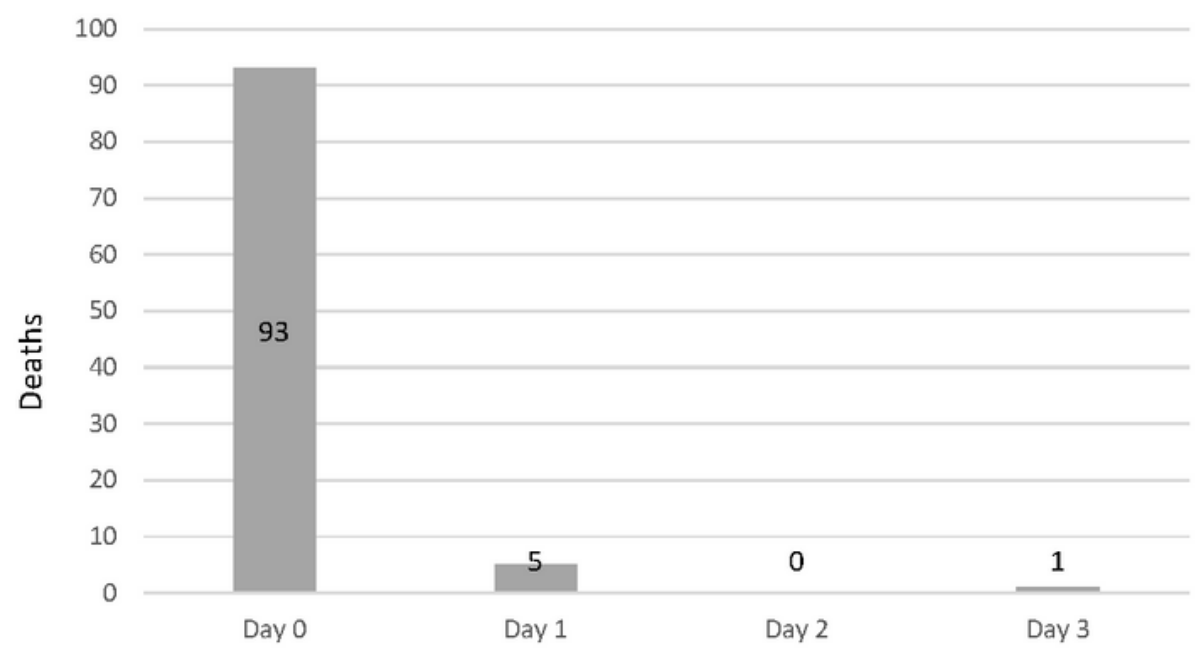

Day 0: died on arrival without return of spontaneuos circulation

Day 1: died within one day

Day 2: died between the 1st and 2 nd day

Day $\mathrm{X}$ : died between $(\mathrm{X}-1)$ and $\mathrm{X}$ day

B. Patients without out-of-hospital cardiac arrest

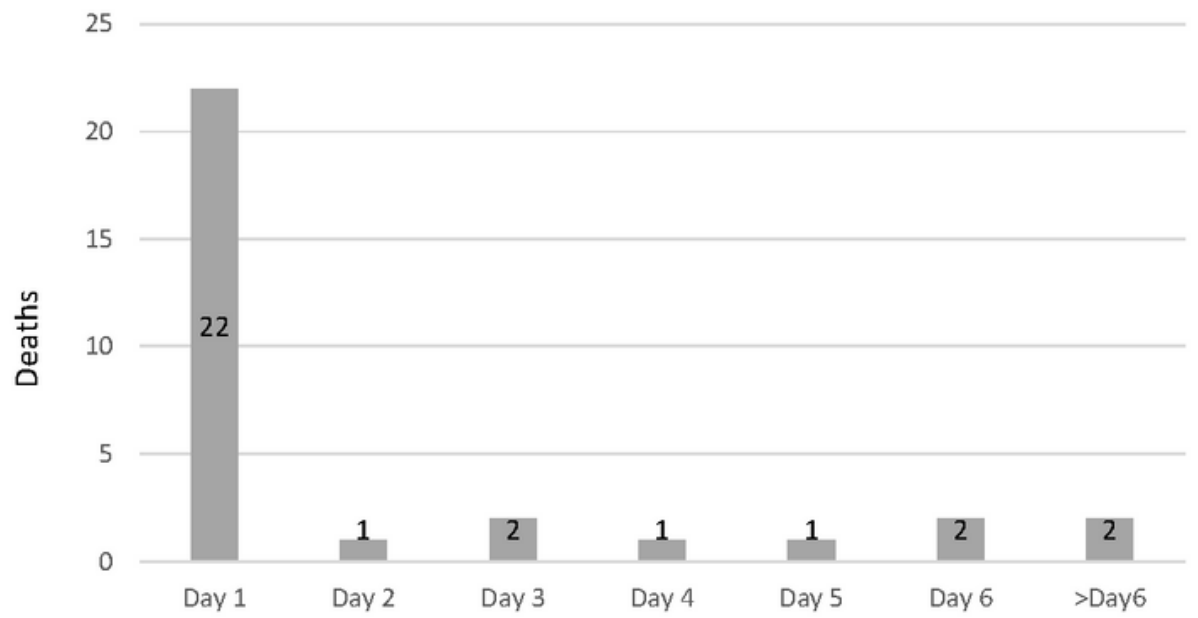

Day 1: died within one day

Day 2: died between the 1st and 2nd day

Day X: died between (X-1) and X day

\section{Figure 2}

The distribution of deaths. A. The patients with out-of-hospital cardiac arrest. B. The patients without cardiac arrest on arrival.

\section{Supplementary Files}


This is a list of supplementary files associated with this preprint. Click to download.

- SupplementaryTable1.docx

- SupplementaryTable2.docx

- SupplementaryTable3.docx 